\title{
UMA ETNOGRAFIA DA GUARDA CIVIL MUNICIPAL DE NITERÓI: formação, paradigmas e senso comum militarizado
}

\author{
Carlos Eduardo Pereira Viana ${ }^{1}$
}

\section{Resumo}

O presente artigo versa sobre o processo de formação profissional da Guarda Civil Municipal de Niterói, no Rio de Janeiro, e lança um olhar sobre uma metodologia de ensino que se utiliza de diversas teorias na construção da identidade de seus agentes, a partir de abordagens que em determinados momentos se contrapõem totalmente, sendo identificadas representações militares provenientes do método de ensino e formação das academias militares do exército e da Polícia Militar. Desta forma, há o destaque de duas ideias de Guarda Civil Municipal. Uma formada a partir de conceitos institucionais civis, e outra ligada ao modus operandis de forças militares, transformando assim os agentes, ao fim de suas formações, em personagens que flutuam entre duas identidades que são manipuladas e ativadas a partir de suas moralidades e códigos de "bom senso" particulares.

Palavras-chave: Segurança Pública, Guarda Civil Municipal, Formação, Militarização

\begin{abstract}
This article aims to study the process of professional training of the Municipal Civil Guard of Niterói, Rio de Janeiro, and a look at a teaching methodology that uses several theories in the construction of the identity of its agents, based on approaches that in certain moments are completely opposed, and military representations from the method of teaching and training of the military academies of the army and the Military Police are identified. In this way, there are two ideas of Municipal Civil Guard. One formed from civil institutional concepts, and another linked to the modus operandis of military forces, thus transforming the agents, at the end of their formations, into characters that float between two identities that are manipulated and activated from their morals and codes of "good sense".
\end{abstract}

Keywords: Public Security, Municipal Civil Guard, Training, Militarization

\footnotetext{
${ }^{1}$ Mestrando em Antropologia pelo Programa de Pós-graduação em Antropologia na Universidade Federal Fluminense (PPGA/UFF). Email: caduviana@live.com
} 


\section{Introdução}

Nascido e criado no Rio de Janeiro até a adolescência, comecei a descobrir Niterói ao caminhar pelas suas ruas com os amigos que as experiências de vida agregaram à minha jornada, e através desse exercício semanal de conhecer a cidade melhor, já que estaria cada vez mais ligado a ela, fui me atentando cada vez mais a algumas práticas e rotinas estabelecidas no ordenamento da cidade, seja em sua zona central ou na zona mais semelhante do ideal socioeconômico da zona sul carioca. Este exercício de observar e absorver tudo ao meu redor já me encaminharia para a antropologia mesmo sem saber o que tal perspectiva representava.

Creio que o meu primeiro contato reflexivo com as questões de Segurança Pública tenha acontecido nesse processo de observar as curiosidades encontradas pelas ruas, seja no espanto diário de ser analisado por diversos policiais militares com seus fuzis ostentados para fora de suas viaturas, na involuntária presença em abordagens policiais no centro da cidade realizada por agentes da Guarda Civil Municipal (GCM) para a apreensão de produtos que os camelôs estavam a vender, na leitura de textos sensacionalistas no jornal sobre a "guerra" que se iniciara ou no contato com colegas que faziam parte de alguma das instituições que compõem a segurança pública do município ou estado.

Foi a partir do contato com um desses colegas, mais especificamente um agente da GCM de Niterói, que comecei a refletir de forma um pouco mais crítica sobre as questões que presenciava diariamente ao caminhar pela cidade, tais como: a minha naturalização de uma postura agressiva dos policiais militares, a violência dos agentes da GCM nas batidas e a sensação de insegurança reforçada pelos jornais para o desenvolvimento de um senso comum positivo ao empenho na dita "guerra" como sendo esta talvez a única saída para a resolução do "problema".

Estas questões, juntamente com uma análise mais crítica do que a observação do cotidiano realizada por um morador da cidade, se interligaram ao meu ingresso na Universidade Federal Fluminense no curso de Ciências Sociais, e assim se mantiveram por alguns períodos até a minha entrada no Instituto de Estudos Comparados em Administração de Conflitos (InEAC-UFF) e no contato com a minha desde então orientadora Lucía Eilbaum e os colegas de pesquisa. De forma praticamente concomitante à minha entrada no grupo, algumas situações interessantes aconteceram. A mais determinante foi o contato com um antigo professor de artes marciais que era ex-policial militar e que se encontrava na GCM de Niterói há pelos menos uma década. 
Este contato me era marcante por ter relação com uma considerável quantidade de relatos feitos por este colega durante os anos em que tivemos um maior ritmo de encontros, tendo inclusive um destes relatos sendo um dos primeiros e mais importantes para as conexões que vim a estabelecer entre os paradigmas civis e militares encontrados dentro da instituição. Ele discordara de determinadas ordens do comando da Guarda, e expôs tais discordâncias. A principal delas era a de que havia dentro da Guarda um costume de se prestar continência para o Comandante Geral da Guarda, que era um policial militar da reserva. Tal ação era algo extremamente irregular já que o regimento da Guarda não previa tal sinal simbólico que é, de fato, ligado a representações militares e não às instituições civis do Estado. Porém já era algo praticamente consolidado informalmente na estrutura da instituição à época de tal comandante, já que era fácil encontrar policiais militares da reserva e expoliciais militares desenvolvendo atividades como agentes da Guarda. A partir desta reclamação ele se tornou uma pessoa não muito bem-vista pelos comandantes, pois "questionou ordens que não deveriam ser questionadas", segundo explicação exposta por ele em uma entrevista já no processo de elaboração desta pesquisa.

Como o fato de um comentário contrário ao estabelecido na prática irregular pelo comando não possuir, e até hoje não possui, nenhuma base para punição, a saída encontrada pelos comandantes foi a de arquitetar uma punição através de algum regimento. A norma que utilizaram para isso foi o mau uso do fardamento e a sua falta de higiene. Após 5 dias sem poder trabalhar e com corte em seus recebimentos, ele voltou ao serviço e continuou ao longo daquela gestão sendo alvo de seletivas aleatoriedades do comando.

Seguindo este e mais uma série de relatos, me interessei por estudar e buscar compreender como tal processo de hierarquia e comando se construía dentro da GCM de Niterói, interessado em visualizar as questões vinculadas às práticas formais e informais estabelecidas dentro da rotina dos agentes e de que forma estes seguiriam um modo de operação que de forma regimentar deveria estar ligado a um paradigma civil, mas que encontrava na realidade um conjunto de práticas, ritos e normas ligados a um paradigma militar.

\section{O campo de pesquisa e o Curso de Formação Profissional}

Enquanto me preparava com a leitura acumulada sobre segurança pública e alguns trabalhos sobre as Guardas Municipais como a coletânea de Miranda, Azevedo e Rocha (2014) sobre saberes e práticas destas instituições, e o livro produto de uma pesquisa com a 
GCM de Niterói realizada por Mello (2011), tive a coincidência do InEAC estabelecer uma parceria com a Prefeitura de Niterói para a elaboração, organização e aplicação de um curso de formação profissional para os agentes da Guarda que seriam integrados ao quadro de servidores municipais após a realização de um concurso público que selecionaria 300 novos agentes.

A partir de meu interesse na pesquisa e no campo, fui convidado pela professora Vivian Paes, até então coordenadora do curso, para participar como monitor das atividades. Assim, pude ali começar a minha trajetória de pesquisa dentro da Guarda Civil Municipal de Niterói. Compartilhei dessa experiência com alguns colegas do curso de Segurança Pública, em uma experiência de troca de conhecimento importante para a nossa formação. O primeiro contato se deu no mês de novembro de 2014 quando tive a oportunidade de participar de um dos primeiros grupos focais realizados para ajudar a construir o currículo do curso.

A função de monitoria demandava basicamente a minha presença em dois horários distintos de acordo com uma escala acordada em conjunto com os outros monitores. Esta escala influenciou o início das minhas atividades de pesquisa exatamente por aliar uma função assumida enquanto parte da organização do curso que como consequência me proporcionaria um acompanhamento regular durante toda a sua aplicação. Sendo assim, variadas situações etnográficas presenciadas e relatadas foram resultados deste acompanhamento semanal onde presenciava todos os tipos de abordagens temáticas da formação dos agentes, desde incontáveis sessões de treinamento da ordem unida até aulas críticas sobre o conceito de segurança comunitária.

Assumi como método um acompanhamento que se realizava nestas duas escalas durante a semana e que variavelmente se associava a mais uma presença em campo para o acompanhamento de mais alguma atividade que poderia levantar questões, debates e situações interessantes etnograficamente de acordo com a temática das aulas da semana. Como, por exemplo, em uma semana onde deveria estar presente enquanto monitor em uma sessão de Ordem Unida na segunda-feira pela manhã e em uma aula de Legislação Eleitoral na quartafeira pela parte da tarde, mas que teria uma aula sobre Políticas Públicas de prevenção e redução de riscos do uso de substâncias legais e ilegais na sexta-feira pela manhã.

Dessa forma, passei a ser inserido na organização e assim pude desenvolver a pesquisa e realizar trabalho de campo observando a rotina dos alunos no Curso. Este curso ganhou dois nomes, um mais usado pelo lado da organização da UFF, que seria o Curso de Capacitação em Políticas Públicas de Segurança Pública, Social e Municipal para a Guarda Civil Municipal de 
Niterói/RJ, e outro mais usado pelo lado da organização da Guarda e da Prefeitura, chamado Curso de Formação Profissional (CFP).

O curso tomou como base a última edição organizada em parceria entre o Núcleo Fluminense de Estudos e Pesquisas da Universidade Federal Fluminense (NUFEP/UFF) representando a Universidade e a Prefeitura do Município de Niterói, realizado nos anos de 2002 e 2003. Curso este que serviu como base para que o Ministério da Justiça e a Secretária Nacional de Segurança Pública (SENASP) desenvolvessem uma matriz curricular nacional voltada para a formação das Guardas Municipais, destacando assim a sua importância e o seu pioneirismo no tratamento do assunto.

As aulas eram ministradas pelos pesquisadores do InEAC/UFF, professores convidados de outras universidades, guardas municipais e funcionários ligados à Prefeitura de Niterói. A metodologia proposta pelo InEAC/UFF consistia na mediação das discussões pelo professor, por meio de raciocínio teórico e prático, algo comum no meio acadêmico, ministrando aulas expositivas com o objetivo de se obter a participação dos guardas municipais sobre as diversas possibilidades de intervenção nas situações cotidianas.

Além da coordenação e dos professores, a equipe do InEAC/UFF ainda era composta por monitores, atividade que desenvolvi por um determinado período de tempo durante o curso, que auxiliavam na aplicação de trabalhos, acompanhavam a rotina de aulas a fim de auxiliar os professores e, por fim, desenvolveriam um relatório sobre toda a sua experiência no curso.

A equipe do InEAC/UFF elaborou uma grade curricular baseada na Matriz Curricular Nacional para a Formação em Segurança Pública, conforme estabelecido pela SENASP para o curso de formação.

Desta forma, as três turmas previstas para o Curso de Formação Profissional seriam orientadas e seguiriam uma escala de 40 horas semanais, de segunda a sexta-feira, com aulas das 8 às 12 horas, seguidas por uma pausa para o almoço, e uma segunda sessão de aulas das 13 às 17 horas.

De forma a sistematizar alguns dados, neste artigo me concentrarei na presença de algumas representações militares que reforçam o entendimento sobre o processo de militarização da segurança pública em uma cadeia informal de práticas que são passadas diariamente no ambiente da Guarda. 


\section{Representações Militarizadas}

O processo da militarização na instituição se dá, notoriamente na interlocução com os agentes e o dia-a-dia da instituição, através da forte influência exercida pelos cargos de comando da Guarda, que historicamente (pelo menos em Niterói) são cargos ocupados por militares oriundos da Polícia Militar. No período em que este trabalho foi desenvolvido, o Secretário de Ordem Pública de Niterói era o Coronel Marcus Jardim, que após a sua morte em decorrência de um câncer, foi substituído por outro Coronel da Polícia Militar, o Coronel Gilson Chagas. Esta reposição reforçou a preferência histórica da Prefeitura de Niterói por um comando militar na instituição, assim como demonstrado por Veríssimo (2009) na Guarda Municipal do Rio de Janeiro em sua Dissertação de Mestrado, onde também foi notado por ele o histórico militar do comando da instituição e as influências que esta prática gerou nas relações de poder internas da Guarda.

Esta preferência por um comando militar através dos anos influenciou direta e indiretamente na postura e na atuação dos agentes, através de práticas informais e até mesmo algumas que foram se formalizando com o passar dos anos dentro da instituição, como na a prática de prestar continência citada acima.

O interessante dessa experiência é notar que os guardas mais antigos sentiram esta transformação informalizada na estrutura da Guarda e, consequentemente, do que significa ser um guarda e todas as questões relacionadas ao seu ethos. Por vezes, ouvi de guardas mais antigos que eles discordavam do comando, pois pensavam estar em uma corporação militar, mas que não, visto que aquela era uma instituição civil onde não haveria espaço para tais conceitos.

O problema deste argumento usado por estes guardas antigos não é a teoria, mas a prática. A prolongada presença de militares à frente dos órgãos policiais no Brasil e o treinamento de sucessivas gerações de policiais em academias e escolas de polícia onde foram submetidos a currículos e metodologias que se inclinavam a perpassar e potencializar a doutrina militar, como destacado por Jorge da Silva (1996) em seu artigo sobre a militarização da segurança pública e a reforma da polícia, evidencia como a Polícia Militar mantém uma lógica de enfrentamento digna das maiores guerras pelo mundo, e ainda como esse discurso, através dos anos, foi fortalecido não apenas dentro das próprias academias de polícia, mas também na sociedade em geral por meio da imprensa, por exemplo.

Cito tal explanação para fazer o paralelo com a lógica encontrada por mim na Guarda, no âmbito do CFP, onde os professores da UFF esboçaram a tentativa de romper com a 
perpetuação desta doutrina militar a partir de suas aulas, as quais visavam um debate crítico sobre as práticas das forças de segurança pública de vários lugares do planeta, possuindo como método de análise uma perspectiva comparada, para assim refletir sobre a realidade encontrada na Guarda. Foi notável que tal tentativa não foi de agrado unânime entre os guardas, e isto era facilmente percebido em seus discursos, conversas e questões feitas para os professores em inúmeras tentativas de provocação e estabelecimento de uma divisão entre teoria e prática. Ainda que alguns se manifestassem a favor de uma nova lógica, de um rompimento com a prática de "guerra" e combate, a maioria ainda investira em um pensamento disposto ao enfrentamento, como nestas passagens retiradas de um trabalho feito em sala de aula pelos guardas onde eles deveriam responder a seguinte questão: "Levando em consideração o tratamento desigual destinado pelo Estado aos cidadãos, discorra sobre o papel das instituições de segurança pública e social na administração de conflitos e na universalização de direitos e de acesso à justiça."

Seguem as respostas de 4 guardas divididos em duas duplas. A primeira dupla respondeu assim:

\begin{abstract}
"Entendo que o tratamento diferenciado em uma favela localizada na zona sul do Rio de Janeiro, deva ser diferente ao tratamento realizado no morro do alemão. Isso não seria uma discriminação, mas sim tratar os desiguais como desiguais na medida de suas desigualdades.

Os policiais realizam apreensões todos os dias de drogas, armamentos e pessoas, mas as leis e o próprio judiciário fazem com que todo esse trabalho seja praticamente nulo pelo fato de os policiais cumprirem o que está na lei e os juízes concederem regalias e privilégios aos criminosos.
\end{abstract}

Um bom exemplo, temos as pessoas que fazem o uso de entorpecentes e a própria lei e uma parcela da sociedade como a UFF, acham que esses usuários são inocentes ou doentes e não criminosos" - lógica militar da guerra as drogas. "São vocês que financiam essa merda!"

Por isso argumento que a própria sociedade não deseja mudanças e tudo isso devido ao fato de que a mesma não está disposta a deixar de comprar drogas ou desejar tratamento de criminoso para quem comete crime. É preciso parar com essa hipocrisia de achar que um usuário de entorpecente é somente um doente como também um cleptomaníaco são doenças aceitáveis.

Criminoso tem que ser tratado como tal e as pessoas devem deixar as policiais fazerem o papel legal dela".

A segunda dupla respondeu da seguinte maneira:

"Entendemos ser de suma importância o papel das instituições de segurança pública para um convívio pacífico e tranquilo no que diz respeito aos cidadãos do bem.

Entretanto para que consigamos chegar nesse ponto é imprescindível que haja um 
confronto direto e árduo com aqueles que estão à margem da lei, ainda que para isso afete pessoas do bem.

Tais confrontos acontecem diariamente com diferentes órgãos de segurança pública como forma de alcançar a paz social. Nós como guardas civis municipais de Niterói também somos parte deste confronto e assim continuaremos até que a paz reine em nosso município".

Tais discursos feitos em sala de aula demonstram como até mesmo os guardas que chegaram recentemente à instituição percebem a conjuntura atual da Segurança Pública brasileira, especificamente a carioca. E corroboram para a análise de que a doutrina militar não se resume apenas aos policiais, e sim que esta doutrina está disseminada na sociedade, pois tais guardas acabaram de ingressar como agentes de segurança pública, trazendo consigo ainda de forma majoritária as percepções adquiridas como um cidadão e não como um agente.

Este foi apenas um dos momentos em que foi percebido o conflito presente na tentativa da ruptura com tal doutrina, empreendida por parte dos professores da UFF. Um segundo momento muito emblemático, foi quando ocorreram as reservas de datas para aulas restritas aos guardas, onde nem mesmo os monitores, professores ou pesquisadores - que seria o meu caso - poderiam estar presentes. Tal fato aconteceu, talvez por coincidência, ou não, após diversas aulas marcadas com uma postura mais questionadora e que tiveram boa aceitação por parte dos guardas novos.

Mas o mais curioso ainda estaria por vir. Foi quando algumas aulas que seriam ministradas pela UFF foram canceladas por motivos diversos e em seus lugares foram postas aulas de ordem unida, nas quais os guardas treinaram por horas seguidas as diversas formações que estariam presentes na cerimônia de formatura, fato que, para o comando da Guarda, justificaria tais aulas.

Meu maior estranhamento diante destas aulas se deu por conta do timing; exatamente após discussões ácidas como a que gerou um debate acalorado sobre a proposta de redução da maioridade penal, onde a turma se dividiu em discursos permeados por moralidades individuais que apareceram tanto nas falas contrárias, quanto nas favoráveis, e propostas que foram bem absorvidas por parte dos alunos para com os professores, o que até então tinha acontecido em raros momentos. O que pude entender pelo fato em si e por conversas informais com os guardas, foi que o próprio comando da guarda estava analisando as aulas como algo que poderia influenciar no pensamento dos guardas de tal forma que problemas poderiam surgir através da formação destes como questionadores da lógica imposta. 


\section{Conclusões}

Visualizo como uma questão importante o fato desse trabalho levantar dois lados de uma instituição e seus agentes. De um lado, a presença de elementos militarizados como o prestar continência, a farda, a ordem unida, músicas herdadas das forças armadas, treinamentos, etc. E do outro lado, um movimento que desperta a possibilidade de uma reflexão acerca da questão do militarismo que possa, eventualmente, alterar, ou pelo menos, refletir sobre o quadro atual.

Vimos esta pré-disposição nos ambientes onde houve a troca de opiniões e debates dentro da sala de aula, nos questionamentos feitos por parte dos guardas novos aos mais antigos, nas questões de hierarquia e comando, e em outros momentos.

O que percebo é a presença do que chamo de senso comum militarizado, onde a opção pelo militarismo se encaixa perfeitamente no atendimento de uma maneira mais óbvia e fácil a um Estado que entende a Segurança Pública como um ambiente de "guerra".

Adotando a ideia de um senso comum militarizado, podemos entender que a grande barreira que se constrói dentro da lógica de segurança pública é, também, uma consequência da própria sociedade, pois é esperado por uma parcela da sociedade um determinado tipo de conduta por parte das forças de segurança, tendo como anseio que sua visão de que "bandido bom é bandido morto" seja atendida. Devemos compreender esse processo de militarização da segurança pública como algo que passa por várias áreas de estudo, com lógicas de combate e com o uso dos termos "guerra" e "luta" como algo bastante presente, como na "guerra ao tráfico" que o Estado do Rio de Janeiro diz praticar há mais duas décadas.

Sendo assim, os agentes, neste caso, são duplamente protagonistas. Primeiro como moradores de favelas e parte da classe baixa, que sofrem com as intervenções violentas do Estado e com a presença do tráfico de drogas e das milícias. Em segundo, a partir de certo momento, como protagonistas destas intervenções só que desta vez fardados, subindo o morro com seus fuzis, táticas de guerra e preparados para matar. E é neste momento em que presenciamos a lógica do "pobre matando pobre" de maneira institucionalizada dentro da política pública do Estado.

\section{Referências bibliográficas}

A SENASP. Competências e criação da SENASP. Disponível em: <http://justica.gov.br/suaseguranca/seguranca-publica/senasp-1/a-senasp>. Acesso em: 23 de Março de 2016. 
BRASIL. LEI N ${ }^{\circ}$ 13.022, DE 8 DE AGOSTO DE 2014. Estatuto Geral das Guardas Municipais. In: http://www.planalto.gov.br/ccivil_03/_Ato2011-2014/2014/Lei/L13022.htm Página acessada em 16/09/2015.

BRASIL. Ministério da Justiça/ Secretaria Nacional de Segurança Pública/ SENASP. Matriz curricular nacional para ações formativas dos profissionais da área de segurança pública / Brasília, 2003.

DA SILVA, Jorge. Militarização da segurança pública e a reforma da polícia: um depoimento. In: BUSTAMANTE, Ricardo et SODRÉ, Paulo César (Coordenadores). Rio de Janeiro: Ensaios jurídicos - O Direito em Revista. Instituto Brasileiro de Atualização Jurídica (IBAJ), 1996, pp. $497-519$.

LIMA, Roberto Kant de. Polícia da cidade do Rio de Janeiro. Rio de Janeiro, RJ: Forense, 1995

MELLO, K. S. S. Cidade e Conflito: guardas municipais e camelôs. 1. ed. Niterói: EDUFF, 2011. 211p.

MIRANDA, A. P. M. (Org.); AZEVEDO, J. S. (Org.); ROCHA, T. M. A. (Org.) Políticas públicas de segurança municipal - Guardas Municipais: saberes e práticas. 1. ed. Rio de Janeiro: Consequência, 2014.

VERÍSSIMO, Marcos. "DE SOL A SOL”, em luta por um lugar ao sol: A Guarda Municipal do Rio de Janeiro e os ritos, conflitos e estratégias do espaço público carioca. 2009. Dissertação (Mestrado em Antropologia) - Universidade Federal Fluminense, Rio de Janeiro.

VIANA, Carlos Eduardo Pereira. - "Aqui não tem Guardinha! Aqui tem Guarda Municipal!": Uma etnografia da Guarda Civil Municipal de Niterói através do Curso de Formação Profissional. 2017. Trabalho de Conclusão de Curso (Graduação em Ciências Sociais) - Universidade Federal Fluminense. 68 f. ; il.

Recebido em: Abril de 2018

Aprovado em: Julho de 2018 